\title{
Frekuensi Ekokardiografi pada Fase Awal Penyakit Kawasaki
}

\author{
Najib Advani \\ Departemen Ilmu Kesehatan Anak, Fakultas Kedokteran Universitas Indonesia Rumah Sakit Dr Cipto Mangunkusumo, Jakarta
}

Latar belakang. Penyakit Kawasaki (PK) merupakan suatu vaskulitis akut, terutama menyerang balita. Aneurisme koroner terjadi pada 15\%-25\% pasien PK yang tidak diobati. Ekokardiografi merupakan sarana non-invasif dengan spesifisitas dan sensitivitas tinggi untuk mendeteksi kelainan koroner pada segmen proksimal. American Heart Association menganjurkan ekokardiografi pada tahap awal, dilakukan tiga kali, yaitu saat diagnosis, 1-2 minggu kemudian dan 4-6 minggu selanjutnya.

Tujuan. Untuk mengetahui apakah pada pasien PK yang tanpa komplikasi, ekokardiografi saat awal cukup dilakukan dua kali berturut turut saja.

Metode. Dilakukan studi retrospektif dari data rekam medis pasien Kawasaki di lima rumah sakit di Jakarta dan Tangerang beserta hasil ekokardiografi serial sejak Januari 2003 sampai Juli 2013. Semua pasien didiagnosis dan ditatalaksana oleh peneliti berdasarkan kriteria AHA 2004. Kriteria inklusi adalah semua pasien yang memenuhi kriteria diagnosis dan ekokardiografi pertama serta kedua hasilnya normal serta ekokardiogarfi diulang serial hingga akhir masa penelitian, minimal satu tahun.

Hasil. Dari 503 pasien Kawasaki pada saat diagnosis, 163 menunjukkan dilatasi koroner dan 340 normal. Di antara 340 pasien tersebut, 228 memenuhi kriteria inklusi dan dilakukan ekokardiografi serial antara 1 hingga 10,5 tahun. Didapatkan bahwa jika hasil ekokardiografi pertama dan kedua normal maka hasil ekokardiografi selanjutnya hingga akhir masa pengamatan tidak tampak kelainan. Kesimpulan. Pada pasien Kawasaki dengan hasil pemeriksaan ekokardiografi pertama dan kedua menunjukkan arteri koroner normal, cukup dilakukan ekokardiografi dua kali dan tidak harus diulang. Hal ini terutama pada pasien yang mengalami kendala akses maupun biaya. Sari Pediatri 2018;20(3):152-7

Kata kunci: penyakit Kawasaki, ekokardiografi

\section{Frequency of Echocardiography at Early Stage of Kawasaki Disease}

Najib Advani

Background. Kawasaki disease (KD) is an acute vasculitis of childhood that leads to coronary artery aneurysms in $15 \%-25 \%$ of untreated cases. Echocardiography is a noninvasive tool and has a high sensitivity and specificity for the detection of coronary artery lesions at the proximal segments. The American Heart Association (2004) recommended for uncomplicated patients, echocardiography should be done at the time of diagnosis, and repeated both within 1 to 2 weeks and 4-6 weeks after treatment.

Objective. To determine whether two consecutive echocardiograms at early stage of KD would be appropriate for uncomplicated patients instead of three as recommended by the American Heart Association.

Methods. We elaborated the medical records of all Kawasaki patients at five hospitals in Jakarta and Tangerang and followed up their course as of January 2003 until July 2013. All patients were diagnosed and managed by the author. Diagnosis was based on American Heart Association consensus on Kawasaki disease 2004. The inclusive criteria were all patients who met the diagnostic criteria with normal coronary arteries on the first and second echocardiograms. Echocardiography was repeated at 4-6 weeks and later followed up until the end of the study period, at least once after one year.

Results. From 503 Kawasaki patients, at the time of diagnosis 163 showed coronary dilatation and 340 without any dilatation. From this 340, 228 met the criteria and had serial echocardiography at least for 1 year until the total of 10.5 years. We found that if the first and the second echocardiograms showed normal coronary arteries, the subsequent ones would also be normal.

Conclusion. In uncomplicated patients, if the first and second echocardiograms are normal, especially for patients with financial and access constraints, the third echocardiography would not be mandatory. Sari Pediatri 2018;20(3):152-7

Keywords: Kawasaki disease, echocardiography

Alamat korespondensi: Najib Advani. Departemen Ilmu Kesehatan Anak, Fakultas Kedokteran Universitas Indonesia Rumah Sakit Dr Cipto Mangunkusumo Jakarta. Email: najib.advani@gmail.com 
Najib Advani: Frekuensi ekokardiografi pada fase awal penyakit Kawasaki

$\mathrm{P}$ enyakit Kawasaki (PK) merupakan suatu vaskulitis dengan demam yang bersifat self limiting, terutama menyerang anak balita. ${ }^{1}$ Etiologi PK hingga saat ini belum diketahui. Saat ini, PK merupakan penyebab utama penyakit jantung yang ditemukan pada anak di negara maju. Terapi pilihan utama pada PK adalah imunoglobulin untuk mencegah terjadinya dilatasi koroner serta pemberian aspirin.

Mengingat tidak adanya pemeriksaan yang patognomonik untuk PK, diagnosis ditegakkan berdasarkan gejala klinis dan menyingkirkan penyakit lain yang mirip. Kriteria klinis untuk menegakkan diagnosis PK dengan tipe komplit adalah demam lima hari atau lebih, kedua mata merah tanpa sekret, bibir dan lidah merah, pembesaran kelenjar getah bening servikal unilateral, eksantema yang polimorfis, serta eritema pada telapak tangan dan kaki. Diagnosis PK dapat ditegakkan jika ditemukan 5 dari 6 tanda klinis tersebut. Sementara untuk tipe yang tidak komplit adalah dengan jumlah tanda klinis yang tidak lengkap. Diagnosis dapat ditegakkan jika ditemukan kelainan koroner pada pemeriksaan ekokardiografi. ${ }^{1}$

Ekokardiografi merupakan pemeriksaan yang non invasif dan mempunyai sensitivitas dan spesifisitas yang tinggi untuk mendeteksi kelainan arteri koroner segmen proksimal. ${ }^{2}$ Pada ekokardiografi fase akut dapat dijumpai vaskulitis arteri koroner, perikarditis, endokarditis dan miokarditis. Ekokardiografi berperan penting pada saat diagnosis, stratifikasi risiko, dan tatalaksana pasien. ${ }^{1-4}$

Pemeriksaan ekokardiografi awal yang dianjurkan berdasarkan konsensus oleh AHA (American Heart Association) tahun 2004 adalah pada saat diagnosis ditegakkan, 1-2 minggu kemudian, dan 4-6 minggu setelah terapi. Jika hasil normal, tidak perlu diulang dalam waktu dekat dan jika terdapat dilatasi koroner maka evaluasi ulang tergantung pada derajat dilatasinya. ${ }^{1}$ Kelainan koroner dijumpai pada 15\%-25\% kasus yang tidak diobati dan menurun mejadi $2 \%-6 \%$ pada kasus yang diberikan imunoglobulin pada 10 hari pertama. ${ }^{1,3,4}$

Mengingat di banyak negara, terutama negara berkembang seperti Indonesia, biaya ekokardiografi tidak murah. Jumlah kardiolog anak maupun sarana ekokardiografi yang kurang, serta akses ke pusat medis yang sulit dan jauh sehingga timbul masalah untuk melakukan ekokardiografi sesuai dengan anjuran AHA (tiga kali ekokardiografi saat awal). Untuk mengatasi hal tersebut, kami melakukan penelitian untuk mengetahui apakah ekokardiografi pada fase awal pasien PK yang belum mengalami dilatasi arteri koroner cukup dilakukan dua kali saja.

\section{Metode}

Kami melakukan penelitian retrospektif dengan mengambil data semua pasien PK yang rawat inap sejak Januari 2003 sampai Juli 2013 di lima rumah sakit di Jakarta dan Tangerang. Dasar diagnosis PK berdasarkan kriteria dari AHA. ${ }^{1}$ Kriteria inklusi adalah semua pasien yang memiliki data lengkap yang memenuhi kriteria PK komplit serta dilakukan ekokardiografi saat diagnosis ditegakkan, 1- 2 minggu dan 4-6 minggu. Selanjutnya, minimal setahun setelah ekokardiografi ketiga. Jadi minimal empat kali ekokardiografi. Ekokardiografi selanjutnya dikerjakan sekitar setahun sekali hingga akhir masa pengamatan. Hanya pasien yang hasil ekokardiografi pertama dan kedua dengan diameter koroner normal yang dimasukkan dalam penelitian ini.

Jika ditemukan kelainan koroner pada eko kardiografi yang pertama atau kedua, pasien di eksklusi. Semua tatalaksana maupun pemeriksaan ekokardiografi sejak awal dilakukan oleh peneliti. Semua pasien mendapatkan terapi imunoglobulin intravena $2 \mathrm{~g} / \mathrm{kgBB}$ dan aspirin dosis tinggi $(80-100 \mathrm{mg} / \mathrm{kg} \mathrm{BB})$ pada fase akut. Studi sudah mendapatkan persetujuan dari Komite Etik.No 420 A/PT02.FK/ETIK/2012.

Untuk menentukan dilatasi arteri koroner, pengukuran dilakukan pada arteri koroner kanan (right coronary artery), arteri koroner kiri utama (left main coronary artery), dan left anterior descending coronary artery. Nilai normal ditetapkan berdasarkan $Z$ score. ${ }^{5}$ Pengukuran dilakukan dengan alat ekokardiografi 2 dimensi yang dilengkapi fasilitas Doppler dengan menggunakan transduser tertinggi yang memungkinkan $(8-12 \mathrm{mHz})$, disesuaikan dengan besar tubuh anak. Dilakukan visualisasi pada berbagai bidang dan berbagai posisi transduser pada semua segmen arteri koroner utama. Pengukuran diameter dilakukan dari tepi dalam ke tepi dalam secara tegak lurus dan menghindari percabangan.

\section{Hasil}

Terdapat 503 pasien rawat inap dengan PK dalam kurun waktu Januari 2003 hingga Juli 2013, 163 
Tabel 1. Karakteristik subyek tanpa dilatasi koroner pada ekokardiografi pertama dan kedua

\begin{tabular}{lccc}
\hline Karakteristik subyek $(\mathrm{n}=228)$ & Jumlah (\%) & Rerata (SB) & Median (min-maks) \\
\hline Jenis kelamin, $\mathrm{n}(\%)$ & & & \\
$\quad$ Lelaki & $150(66)$ & & \\
Perempuan & $78(34)$ & $41,46(31,11)$ & $32,35(3-156)$ \\
Usia (bulan) & & $15,44(7,96)$ & \\
Berat badan (kg) & & 23 & $41(12-126)$ \\
Lama pengamatan (bulan) & & & \\
\hline
\end{tabular}

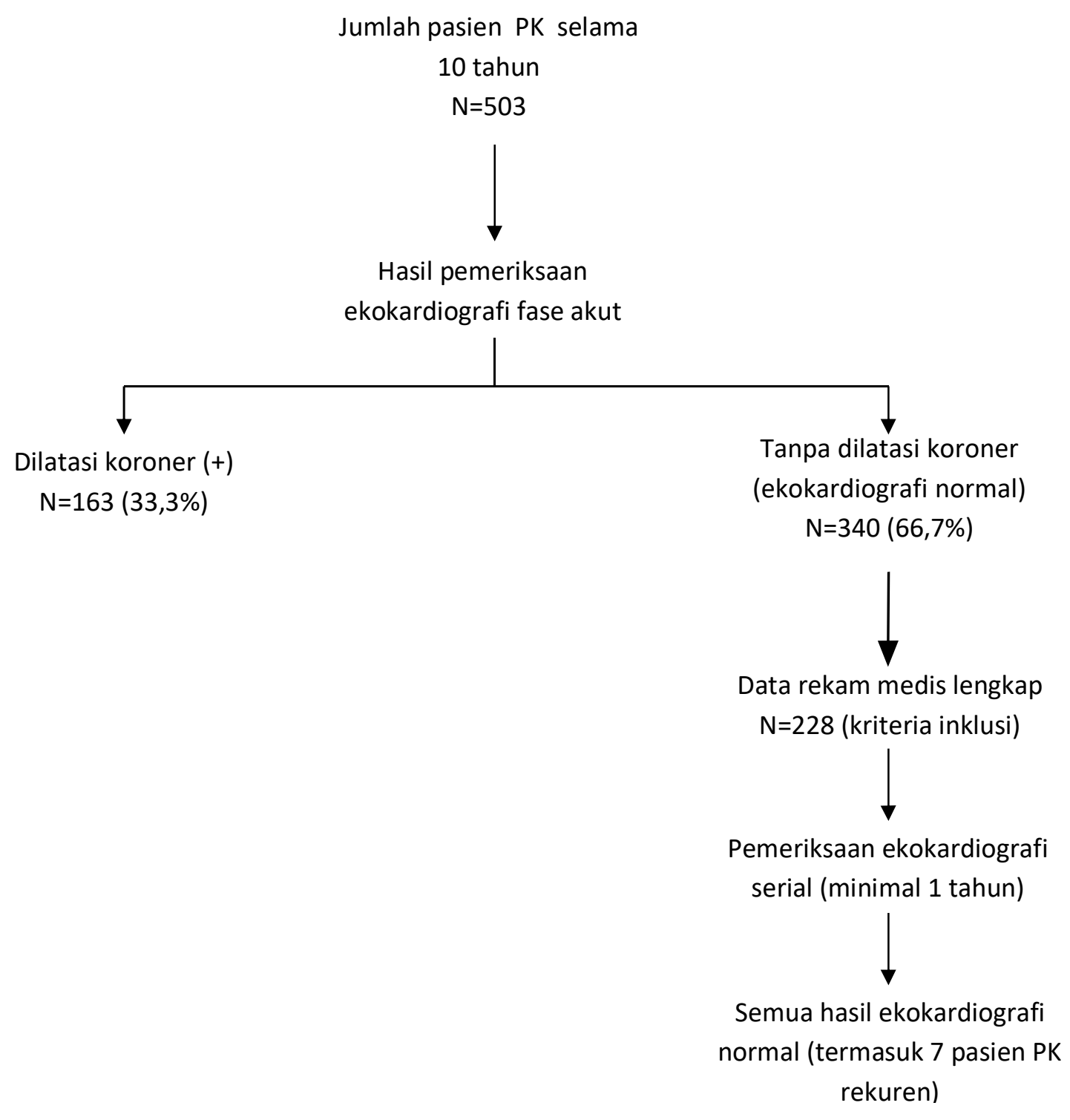

Gambar 1. Rekrutmen subjek dan hasil pemeriksaan ekokardiografi 


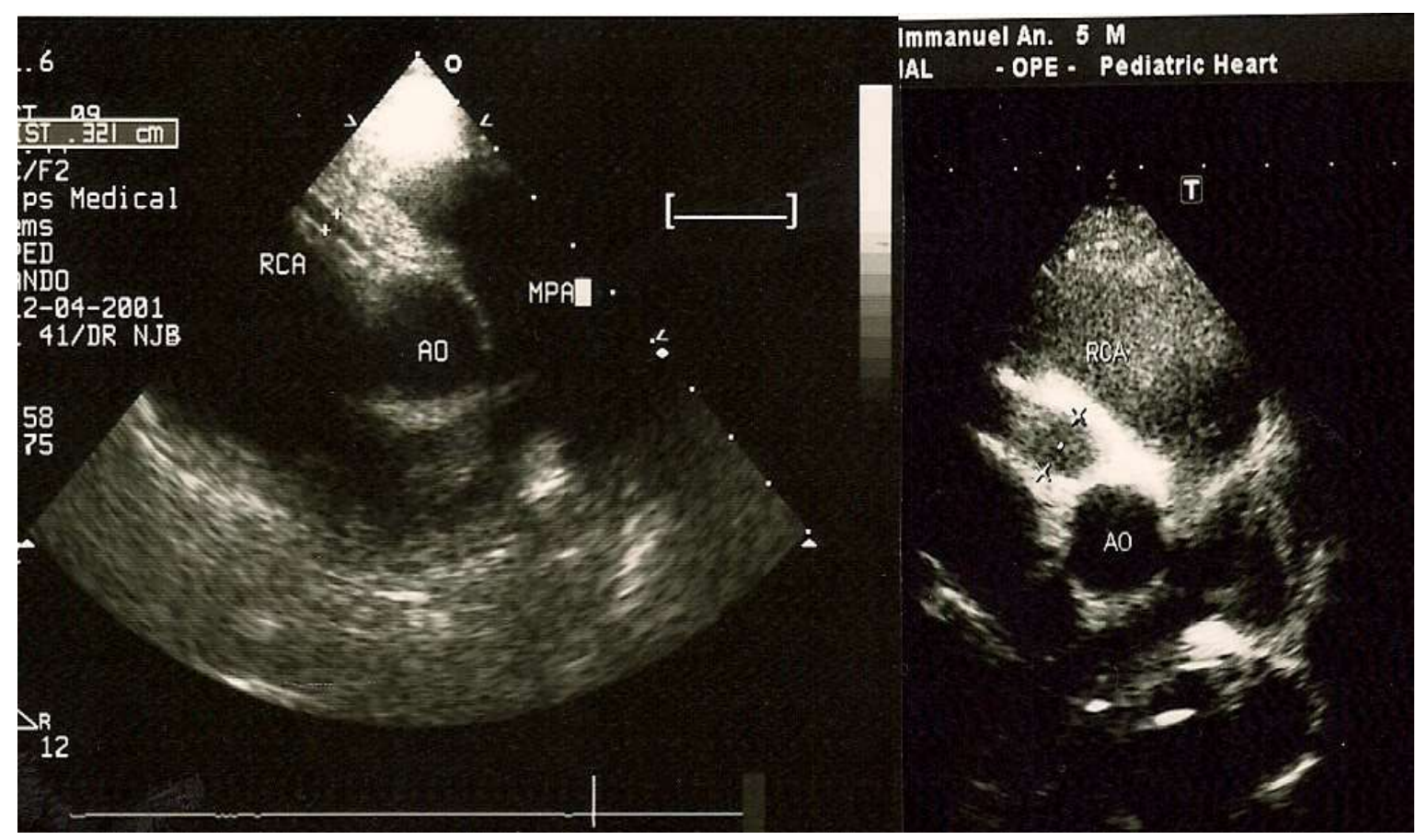

Gambar 2. Perbandingan diameter arteri koroner kanan (RCA) yang normal (gambar kiri) dan aneurisme raksasa (gambar kanan) pada ekokardiografi dengan pandangan sumbu pendek parasternal. RCA:right coronary artery, AO: aorta; MPA: main pulmonary artery.

di antaranya menunjukkan dilatasi koroner pada ekokardiografi pertama pada fase akut $(33,3 \%)$. Terdapat $340(67,7 \%)$ pasien tanpa dilatasi koroner dan 228 di antaranya memenuhi kriteria serta telah dilakukan ekokardiografi serial bervariasi antara 1 hingga 10,5 tahun. Karakteristik subjek tertera pada Tabel 1.

Kami mendapatkan bahwa jika hasil ekokardiografi pertama dan kedua (interval sekitar 1-2 minggu) menunjukkan arteri koroner normal maka hasil ekokardiografi yang ketiga (interval 4-6 minggu dari ekokardiografi pertama) dan seterusnya (interval minimal setahun dari ekokardiografi ketiga sampai tahun kesepuluh) semuanya menunjukkan hasil yang normal.

Terdapat 7 (3\%) pasien yang tanpa kelainan koroner yang dalam pengamatan mengalami PK rekuren. Semuanya pada kurun waktu 6 bulan hingga 3 tahun setelah awitan pertama. Pada pasien dengan PK rekuren pun kami mendapatkan hasil yang sama (Gambar 1).

\section{Pembahasan}

Pengamatan ini kami lakukan pada pasien Kawasaki yang sejak awal tidak ditemukan komplikasi dilatasi koroner. Pada pasien yang mengalami dilatasi koroner sejak awal, kami mendapatkan bahwa 77,4 \% dilatasi koroner yang sedang dan ringan akan kembali normal (regresi) dalam 2 tahun pertama, sedangkan pada aneurisme raksasa (giant aneurysm) cenderung menetap (Gambar 2). ${ }^{6}$

Pasien Kawasaki ditandai oleh inflamasi sistemik pada arteri ukuran sedang pada berbagai organ dan jaringan saat fase akut. Mekanisme terjadinya dilatasi koroner diperkirakan juga adalah suatu proses inflamasi yaitu terjadi arteritis nekrotikans yang merusak dinding koroner sehingga terjadi aneurisme. ${ }^{1}$

Pada pengamatan jangka panjang terhadap 228 pasien PK dengan rentang waktu 12-126 bulan, tidak ditemukan dilatasi koroner pada semua pasien yang pada kedua ekokardiografi awalnya normal. Hasil yang 
kami dapat sesuai dengan yang dilaporkan beberapa peneliti di negara lain. ${ }^{7-9}$ Mengingat rekomendasi dari AHA tahun 2004 yang menganjurkan pemeriksaan ekokardiografi pada tahap awal PK sebanyak tiga kali ${ }^{1}$ maka untuk pasien yang tidak bermasalah dengan kontrol lanjutan baik dari segi biaya, akses maupun fasilitas, dapat tetap mengikuti anjuran AHA tersebut, yaitu ekokardiografi pada 0, 1-2 dan 4-6 minggu setelah terapi immunoglobulin.

Sementara itu, bagi mereka yang kesulitan untuk kontrol maka ekokardiografi cukup dilakukan dua kali, yaitu saat diagnosis dan sekitar 1-2 minggu setelahnya. Jadi perbedaan hanya satu kali, yaitu tidak dilakukan ekokardiografi yang ketiga. Jika dikaji dari perbedaan biaya adalah penghematan satu kali pemeriksaan atau sekitar 33\% dari total biaya. Jika diterjemahkan dalam biaya konsultasi dan ekokardiografi, jumlahnya juga relatif tidak terlalu besar.

Namun, mengingat penyebaran penduduk yang jauh dari pusat kardiologi anak, hal tersebut dapat menghemat biaya transportasi, akomodasi, dan waktu. Sebagai contoh, beberapa kasus datang dari Papua atau Indonesia Timur. Dibutuhkan biaya yang besar untuk transportasi dan akomodasi untuk mencapai rumah sakit rujukan. Untuk pasien JKN (Jaminan Kesehatan Nasional), juga dapat meringankan beban pemerintah. Jadi untuk pasien yang tinggal jauh maupun dana yang terbatas kita dapat memberikan opsi boleh datang atau tidak datang untuk kontrol yang ketiga sepanjang hasil ekokardiografi pertama dan kedua menunjukkan koroner yang normal.

Sebagai tambahan, tentunya tindakan ekokardiografi serta teknik pengukuran dilakukan secara benar dan mengikuti kaidah yang berlaku. Oleh sebeb itu, diperlukan kemampuan dan pengalaman yang cukup dari kardiolog anak yang melakukan serta kesediaannya untuk belajar terus agar mendapatkan hasil yang optimal. Pasien yang datang dengan arteri koroner normal pada ekokardiografi awal, mayoritas $(82,3 \%)$ datang sebelum hari ketujuh. Hal tersebut dapat dipahami dan sesuai penelitian kami sebelumnya bahwa lama demam setelah hari ketujuh merupakan faktor risiko terjadinya dilatasi koroner. ${ }^{10}$

\section{Kesimpulan}

Pada pasien Kawasaki yang mengalami hambatan baik dari segi biaya maupun akses untuk kontrol pemeriksaan ekokardiografi, jika ekokardiografi pertama saat diagnosis dan yang kedua sekitar 1-2 minggu selanjutnya menunjukkan hasil koroner yang normal, maka ekokardiografi selanjutnya tidak mutlak diperlukan.

\section{Ucapan terima kasih}

Kami mengucapkan terima kasih kepada dr Lucyana Alim Santoso dan dr Christine atas bantuannya dalam pengumpulan data.

\section{Daftar pustaka}

1. Newburger JW, Takahashi M, Gerber MA, Gewitz MH, Tani LY, Burns JC, dkk. Diagnosis, treatment, and long-term management of Kawasaki disease: A statement for health professionals from the Committee on Rheumatic Fever, Endocarditis and Kawasaki Disease, Council on Cardiovascular Disease in the Young, American Heart Association. Circulation 2004;110:2747-71.

2. Capannari TE, Daniels SR, Meyer RA, Schwartz DC, Kaplan S. Sensitivity, specificity and predictive value of twodimensional echocardiography in detecting coronary artery aneurysms in patients with Kawasaki disease. J Am Coll Cardiol 1986;7:355-360.

3. Newburger JW, Takahashi M, Burns JC. Kawasaki disease. J Am Coll Cardiol. 2016;67(14):1738-1749. doi: 10.1016/j. jacc.2015.12.073.

4. Friedman KG, Gauvreau K, Hamaoka-Okamoto A, Tang A, Berry E, Tremoulet AH, Mahavadi VS, Baker A, deFerranti SD, Fulton DR, Burns JC, Newburger JW. Coronary artery aneurysms in Kawasaki disease: Risk factors for progressive disease and adverse cardiac events in the US population. J Am Heart Assoc 2016;5:e03289.

5. de Zorzi A, Colan SD, Gauvreau K, Baker AL, Sundel RP, Newburger JW, dkk. Coronary artery dimensions may be misclassified as normal in Kawasaki disease. J Pediatr 1998;133:254-8.

6. Advani N, Sastroasmoro S, Ontoseno T, Uiterwaal CS. Long-term outcome of coronary artery dilatation in Kawasaki disease. Ann Pediatr Card 2018;11:125-9

7. Lee MH, Dai ZK, Lee MS, Hsu JH, Chuang HY, Wu JR. The recommended frequency of echocardiography in follow up evaluation of patients with Kawasaki disease. Acta Paediatr Taiwan 2005:46:346-51.

8. Scott JS, Ettedgui JA, Neches WH. Cost-effective use of echocardiography in children with Kawasaki disease. Pediatrics 
1999; 104:e57-e59.

9. Tuohy AMM, Tani LY, Cetta F, Lewin MB, Eidem BW, Van Buren P dkk. How many echocardiograms are necessary for follow- up evaluation of patients with Kawasaki disease. Am
J Cardiol 2001;88:328-30

10. Advani.N. Penyakit Kawasaki: faktor risiko terjadinya aneurisme koroner, perjalanan klinisnya, serta jumlah dan kualitas sel progenitor endotel, disertasi. Jakarta: FKUI, 2014. 